\title{
Fatores associados à anemia em adolescentes escolares: Um estudo transversal
}

\author{
Factors associated with anemia in school teenagers: A cross-sectional study \\ Factores asociados con anemia en adolescentes escolares: Un estudio transversal
}

Recebido: 31/03/2021 | Revisado: 11/04/2021 | Aceito: 14/04/2021 | Publicado: 26/04/2021

\author{
Shirley Pereira da Paiva Alves \\ ORCID: https://orcid.org/0000-0003-3090-6033 \\ Universidade Estadual da Paraíba, Brasil \\ E-mail:shirleynutricionista@gmail.com \\ Mônica Oliveira da Silva Simões \\ ORCID: https://orcid.org/0000-0002-5803-599X \\ Universidade Estadual da Paraíba, Brasil \\ E-mail:monicasimoes.uepb@gmail.com \\ Kleber Napoleão Nunes de Oliveira Barros \\ ORCID: https://orcid.org/0000-0003-2515-3292 \\ Universidade Federal Rural de Pernambuco, Brasil \\ E-mail: kleber.barros@ufrpe.br \\ Rayli Maria Pereira da Silva \\ ORCID: https://orcid.org/0000-0002-7915-9553 \\ Centro Universitário UNIFACISA, Brasil \\ E-mail:raylipsilva@gmail.com \\ Amanda Maria Guimarães Barros \\ ORCID: https://orcid.org/0000-0002-0963-4523 \\ Universidade Estadual da Paraíba, Brasil \\ E-mail:amanda.guiimaraes@hotmail.com \\ Carla Campos Muniz Medeiros \\ ORCID: https://orcid.org/0000-0002-7994-7277 \\ Universidade Estadual da Paraíba, Brasil \\ E-mail:carlamunizmedeiros@hotmail.com \\ Danielle Franklin de Carvalho \\ ORCID: https://orcid.org/0000-0003-4835-082X \\ Universidade Estadual da Paraíba, Brasil \\ E-mail:daniellefranklin6@gmail.com
}

\begin{abstract}
Resumo
Introdução: A anemia por deficiência de ferro é um problema de saúde pública com significativa prevalência entre os adolescentes. Essa patologia provoca a redução da concentração de hemoglobina sérica, comprometendo o transporte de oxigênio para os tecidos corporais, causando fadiga, redução da função cognitiva, atraso no crescimento ponderoestatural e no desenvolvimento motor, além de acarretar danos ao sistema imunológico, ao desempenho físico em todas as fases da vida. Objetivo: Identificar os fatores associados à prevalência da anemia em adolescentes de escolas públicas. Métodos: Estudo transversal, descritivo, retrospectivo, com uma amostra de 512 adolescentes escolares. Utilizou-se informações socioeconômicas e demográficas, resultados de exames de hemograma e de Proteína C reativa - PCR, bem como, dados antropométricos e de consumo alimentar. Resultados: Na amostra, houve prevalência de anemia em adolescentes do sexo feminino $20(3,9 \%)$ p-valor $(0,0013)$. O consumo alimentar das adolescentes era inadequado em frutas, legumes e verduras. Conclusão: $\mathrm{O}$ principal fator associado à prevalência da anemia foi o sexo feminino.
\end{abstract}

Palavras-chave: Anemia; Adolescente; Estado nutricional; Consumo de alimentos; Proteína C-Reativa.

\begin{abstract}
Introduction: Iron deficiency anemia is a public health problem with significant prevalence among adolescents. This pathology causes a reduction in the concentration of serum hemoglobin, compromising the transport of oxygen to body tissues, causing fatigue, reduced cognitive function, delay in weight-statural growth and motor development, in addition to causing damage to the immune system, to performance physical at all stages of life. Objective: To identify the factors associated with the prevalence of anemia in adolescents from public schools. Methods: Cross-sectional, descriptive, retrospective study, with a sample of 512 school adolescents. Socioeconomic and demographic information, results of blood tests and C-reactive protein (PCR) tests were used, as well as anthropometric and food consumption data. Results: In the sample, there was a prevalence of anemia in female adolescents 20 (3.9\%) p-value (0.0013). Adolescent food consumption was inadequate in fruits and vegetables. Conclusion: The main factor associated with the prevalence of anemia was the female sex.
\end{abstract}

Keywords: Anemia; Adolescent; Nutritional status; Diet, Food and Nutrition; C-reactive protein. 


\begin{abstract}
Resumen
Introducción: La anemia ferropénica es un problema de salud pública con una prevalencia significativa entre los adolescentes. Esta patología provoca una reducción de la concentración de hemoglobina sérica, comprometiendo el transporte de oxígeno a los tejidos corporales, provocando fatiga, disminución de la función cognitiva, retraso en el crecimiento peso-estacionario y desarrollo motor, además de provocar daños al sistema inmunológico, al rendimiento. físico en todas las etapas de la vida. Objetivo: Identificar los factores asociados a la prevalencia de anemia en adolescentes de escuelas públicas. Métodos: estudio transversal, descriptivo, retrospectivo, con una muestra de 512 adolescentes escolares. Se utilizó información socioeconómica y demográfica, resultados de análisis de sangre y pruebas de proteína $\mathrm{C}$ reactiva (PCR), así como datos antropométricos y de consumo de alimentos. Resultados: En la muestra, hubo una prevalencia de anemia en mujeres adolescentes $20(3.9 \%)$ p-value (0.0013). El consumo de alimentos de los adolescentes fue inadecuado en frutas y verduras. Conclusión: el principal factor asociado a la prevalencia de anemia fue el sexo femenino.
\end{abstract}

Palabras clave: Anemia; Adolescente; Estado nutricional; Consumo de alimentos; Proteína C-reactiva.

\title{
1. Introdução
}

Os adolescentes representam uma população mundial de aproximadamente 2 bilhões de pessoas, com idades entre 10 e 19 anos. Nesta fase da vida, que se estabelece entre a infância e a vida adulta, ocorrem intensas transformações fisiológicas, perda de sangue menstrual em meninas e aumento da massa muscular, decorrentes do estirão de crescimento e desenvolvimento biológico, ósseo e sexual, que podem influenciar no nível de ferro do organismo (Oliveira et al., 2015; Thomas et al, 2015; World Health Organization [WHO], 2018).

A adolescência é marcada pela autonomia familiar, pela influência da mídia e dos pares, de modo que seu comportamento alimentar sofre grandes mudanças, sendo comum observar a adoção de hábitos alimentares não saudáveis, bem como a substituição das principais refeições por lanches (Oliveira et al., 2015).

Além disso, a insegurança alimentar e nutricional limita ainda mais o consumo de alimentos saudáveis, pois, no mundo, aproximadamente 6,8 milhões de adolescentes não têm acesso a fontes adequadas de alimentos nutritivos, fazendo com que este período seja marcado por um estado nutricional inadequado, com graves deficiências nutricionais, necessitando de intervenções para reduzir a insegurança e a falta de diversidade alimentar (Akseer et al., 2017).

O comportamento alimentar inadequado dos adolescentes brasileiros foi evidenciado pela Pesquisa Nacional de Saúde do Escolar, que apontou uma redução no consumo de alimentos in natura e o aumento no consumo de alimentos industrializados (Costa et al., 2018).

Essas significativas mudanças nos padrões dietéticos e nutricionais da população, associadas à insegurança alimentar, têm cooperado para o processo de transição nutricional, caracterizado pela redução na prevalência da desnutrição e no aumento expressivo do sobrepeso e da obesidade (Souza et al, 2017). No Brasil, em 2015, confirmou-se uma prevalência de, aproximadamente, $3 \%$ de adolescentes desnutridos, $23,7 \%$ com excesso de peso e 7,3\% de obesos (Instituto Brasileiro de Geografia e Estatística [IBGE], 2016).

Devido à má alimentação e ao alto requerimento de nutrientes na adolescência, pode ocorrer o surgimento da anemia ferropriva. Estima-se que aproximadamente 2 bilhões de pessoas estejam anêmicas. Entre os adolescentes, a prevalência da anemia é de 27\% em países em desenvolvimento e 6\% em países desenvolvidos (Bezerra et al, 2018; Tesfaye et al, 2016). Segundo a Organização Mundial da Saúde (OMS), espera-se que 2,5\% de uma população normal apresente anemia. Portanto, a anemia por deficiência de ferro é considerada um problema de saúde pública quando a sua prevalência é maior que 5,0\% na população (WHO, 2011).

A anemia é definida pela OMS como a concentração de hemoglobina no sangue num nível menor que o esperado, levando-se em conta fatores como idade, sexo, gestação e certos fatores ambientais, como altitude. Além da hemoglobina $(\mathrm{Hb})$ e hematócrito (Ht), o volume corpuscular médio (VCM), a hemoglobina corpuscular média (HCM) e o Red Cell Distribution Width (RDW) são índices utilizados para o diagnóstico de anemia ferropriva. Nos contadores hematológicos, a primeira 
evidência de deficiência de ferro é o aumento do RDW, o qual se altera de forma precoce, antes mesmo da variação de outros parâmetros, como o VCM e a redução da hemoglobina (Hb) (Machado et al, 2019; WHO, 2011).

A anemia provoca a redução da concentração de hemoglobina sérica, comprometendo o transporte de oxigênio para os tecidos corporais, causando fadiga, palpitação, redução da função cognitiva, atraso no crescimento pondero-estatural e no desenvolvimento motor, além de acarretar danos ao sistema imunológico, ao desempenho físico e profissional em todas as fases da vida. Em decorrência disso, os anos de vida perdidos por adolescentes, medidos através do DALY - Disability Adjusted Life Years, indicador composto que avalia a perda de saúde devido à carga de doenças fatais e não fatais, através da soma dos anos de vida perdidos pela mortalidade prematura (YLLs) e anos de vida vividos com deficiência (YLDs), são atribuídos, em sua maioria, à anemia por deficiência de ferro, especialmente na faixa etária de 10 a 14 anos (Akseer et al., 2017; Bezerra et al., 2018; Machado et al., 2019; Urrechaga et al., 2016).

Muitos fatores envolvidos na etiologia da anemia ferropriva são determinados pela condição socioeconômica, a escolaridade, o acesso a alimentos em quantidade e qualidade suficiente, e as enteroparasitoses (Lopes, 2016). Mesmo presente em todos os extratos sociais, a anemia é mais prevalente em países em desenvolvimento, principalmente em comunidades com piores condições de saúde e vida (Silva et al., 2015).

A prevalência da anemia em adolescentes obesos foi relacionada a uma ingestão inadequada de nutrientes, provocando uma dupla carga nutricional (Souza et al., 2017). Porém, outros estudos evidenciam que a prevalência da anemia em indivíduos obesos resulta de processos inflamatórios típicos da obesidade, os quais provocam o aumento dos níveis de hepcidina, promovendo má absorção do ferro (Hutchinson, 2016; Murillo-Ramos et al., 2016; Souza et al., 2016).

Nestes processos inflamatórios, além da hepcidina, há aumento da proteína C-reativa (PCR), desencadeada pela liberação de alguns tipos de citocinas. Muitos estudos envolvendo a análise da PCR apresentaram aumento estatisticamente significativo em indivíduos obesos, corroborando no uso desta proteína como um importante marcador inflamatório na obesidade (Hutchinson, 2016; Nazif et al., 2015).

Considerando a anemia como uma deficiência nutricional grave, tanto por seu impacto na saúde como por sua prevalência no mundo, se faz necessário a investigação dos fatores associados à prevalência da mesma em adolescentes, pois a OMS reconhece esta fase da vida como um período potencial para recuperar a saúde e evitar o efeito intergeracional das doenças (Akseer et al., 2015; Oliveira et al., 2015).

Diante desse cenário, o objetivo do trabalho baseou-se em responder à pergunta condutora: Quais fatores estão associados à prevalência da anemia em adolescentes de escolas públicas?

\section{Metodologia}

O Estudo foi desenvolvido em conformidade com a declaração de Helsinque da Associação Médica de Mundial WMA na versão atualizada em 2013 e foi aprovado pelo Comitê de Ética em Pesquisa, CAEE: 26793219.7.0000.5187

Desenvolveu-se o estudo de modo observacional, transversal, retrospectivo e descritivo de abordagem quantitativa (Pereira, A.S. et al, 2018). Após a aprovação do Comitê de Ética em Pesquisa, teve sua coleta de dados realizada entre janeiro e março de 2020, no arquivo do Núcleo de Estudo e Pesquisa Epidemiológica - NEPE, da Universidade Estadual da Paraíba UEPB. Os dados foram oriundos do projeto financiado sob o edital "Universal-CNPq N 14/2012" e intitulado "Doença aterosclerótica subclínica em adolescentes escolares: relação com o escore Pathobiological Determinants of Atherosclerosis in Youth, Proteína C Reativa ultrassensível e função pulmonar", realizado entre os meses de setembro de 2012 e junho de 2013, em escolas públicas do ensino médio do município de Campina Grande, estado da Paraíba, Brasil.

$\mathrm{Na}$ pesquisa fonte para este estudo, a população foi composta por adolescentes com idade entre 15 e 19 anos, de ambos os sexos, matriculados em escolas públicas da área urbana do município de Campina Grande- PB. O cálculo amostral 
foi determinado por meio da fórmula de prevalência, considerando o número total de alunos matriculados no ensino médio de escolas públicas da zona urbana do município (9294 escolares distribuídos em 264 turmas), uma estimativa de proporção de $50 \%$, erro amostral de 5\%, efeito do desenho (deff) de 1,5 (fator de correção para amostragem aleatória por conglomerado) e um acréscimo de $3 \%$ para eventuais perdas ou recusas. A amostra mínima estimada foi, portanto, de 570 escolares. Foram contactados 583 adolescentes, porém houve sete exclusões (duas por gravidez, quatro por uso de corticoide e um por imobilização do membro inferior), resultando em 576 indivíduos avaliados.

A amostragem foi por conglomerado e estratificada, com partilha proporcional, considerando o porte da escola, pequeno (até 300 alunos), médio (de 301 a 500) ou grande (mais de 500 alunos). A unidade amostral considerada foi a turma e foram incluídos na pesquisa todos os alunos das turmas sorteadas que atenderam aos critérios de inclusão e que aceitaram participar da pesquisa, mediante consentimento escrito, seu ou de seus pais e/ou responsáveis, de acordo com a faixa etária. Considerando-se o número médio de 15 alunos por turma verificado previamente no estudo piloto, foram sorteadas 39 turmas distribuídas em dezoito escolas, sendo onze turmas em sete escolas de pequeno porte, quinze em seis de médio porte e treze em cinco de grande porte, de modo a respeitar a proporção de escolas/alunos/turmas. Foram excluídos do estudo indivíduos que apresentassem doença que ocasionasse prejuízo da atividade física, insuficiência hepática e síndrome nefrótica, hipertensão arterial, diabetes tipo 1, gravidez ou puerpério.

Para a realização deste estudo, foram incluídos os dados extraídos dos formulários de 512 adolescentes, pois apenas estes dispunham de todas as informações necessárias à realização desta pesquisa. Os dados foram duplamente digitados e depois validados pelo subprograma Validate do Epi Info 6.04.

A idade foi avaliada em anos e o sexo como masculino e feminino. A escolaridade materna foi verificada em anos completos e classificada em duas categorias: menor que 9 anos e 9 anos ou mais (Lei no 11.274, 2006).

A classificação do nível socioeconômico das famílias, o estudo utilizou os "Critérios de Classificação Econômica do Brasil", estabelecidos pela Associação Brasileira de Empresas de Pesquisa (Associação Brasileira de Empresas de Pesquisa [ABEP], 2010).

O Consumo alimentar foi classificado através da frequência do consumo, alimentos consumidos mais que 5 vezes por semana ou menos que 5 vezes por semana, utilizando como referência, as porções diárias recomendadas pela Vigilância de Fatores de Risco e Proteção para Doenças Crônicas por Inquérito Telefônico/2009 (Brasil, 2009).

Para avaliar anemia na população estudada, foram considerados os parâmetros de hemoglobina menor que $12 \mathrm{mg} / \mathrm{dL}$ e $13 \mathrm{mg} / \mathrm{dL}$ e hematócrito menor que $36 \%$ e $39 \%$, respectivamente, no sexo feminino e masculino. Avaliou-se ainda os índices hematimétricos para rastrear a deficiência de ferro de modo precoce, sendo consideradas as seguintes alterações: Volume Corpuscular Médio (VCM) menor que 78fl para meninas menores de 18 anos, 81fl para meninas maiores de 18 anos, menor que 79fl para meninos menores de 18 anos e 80fl para meninos maiores de 18 anos; Hemoglobina Corpuscular Média (HCM) menor que 26 pcg para meninas e menor que 27 pcg para meninos; Red Cell Distribution Width (RDW) valores maiores que 13,9\% e 15,8\% para menores de 18 anos e maiores de 18 anos, respectivamente. Para inferir processos inflamatórios, foi utilizado o exame da Proteína C reativa, os valores acima de 3mg/L caracterizaram inflamação (Suhett et al., 2019; WHO, 2011).

O estado nutricional foi classificado de acordo com o IMC em escore z, construído a partir da razão do peso (em quilogramas) pelo quadrado da estatura (em metros), segundo a idade e sexo: baixo peso $(-3 \leq$ escore $\mathrm{z}<-2)$, eutrofia $(-2 \leq$ escore $\mathrm{z}<+1)$, sobrepeso $(+1 \leq$ escore $\mathrm{z}<+2)$, obesidade $(+2 \leq$ escore $\mathrm{z}<+3)$ (WHO, 1995).

As análises estatísticas foram realizadas com uso do software estatístico $R$, versão 3.5.3, e sua interface gráfica $R$ studio, versão 1.1.463. Verificou-se os principais índices hematimétricos estratificados por sexo. Por serem poucos os dados ausentes, as variáveis com missing values não foram descartadas. As interações não foram consideradas para o trabalho por se 
tratar de um estudo descritivo. As quantidades de informações perdidas são informadas quando necessárias e deduzidas do total das variáveis para o cálculo das estatísticas de teste. O teste exato de Fisher foi calculado para quantificar a associação entre as variáveis. A magnitude das associações foi expressa por meio da razão de chances e respectivos intervalos de confiança. Para todos os procedimentos inferenciais utilizados, foi adotado um nível de significância de 5\%, considerando estatisticamente significante $p<0,05$.

\section{Resultados}

Dos 512 adolescentes que compuseram a amostra, 169 (33\%) eram do sexo masculino e 343 (67\%) do sexo feminino. As idades variaram entre 15 e 19 anos, sendo que 59\% deles tinha menos de 17 anos de idade (Tabela 1).

Tabela 1 - Principais características da amostra dos adolescentes escolares 2012-2013.

\begin{tabular}{|c|c|c|c|}
\hline Variáveis & $\mathrm{N}$ & $\%$ & IC 95\% \\
\hline \multicolumn{4}{|l|}{ Sexo } \\
\hline Masculino & 169 & 33 & $28,9-37,1$ \\
\hline Feminino & 343 & 67 & $62,9-71,1$ \\
\hline \multicolumn{4}{|l|}{ Anemia } \\
\hline Sim & 20 & 3,9 & $2,2-5,6$ \\
\hline Não & 492 & 96,1 & $94,4-97,8$ \\
\hline \multicolumn{4}{|l|}{ Idade } \\
\hline$<17$ & 302 & 59 & $54,7-63,2$ \\
\hline$\geq 17$ & 210 & 41 & $36,8-45,3$ \\
\hline \multicolumn{4}{|l|}{ Estado Nutricional } \\
\hline Baixo peso & 29 & 5,7 & $3,7-7,7$ \\
\hline Eutrofia & 414 & 80,9 & $77,5-84,3$ \\
\hline Sobrepeso & 53 & 10,3 & $7,7-13,0$ \\
\hline Obesidade & 16 & 3,1 & $1,6-4,6$ \\
\hline \multicolumn{4}{|c|}{ Escolaridade da Mãe * } \\
\hline$<9$ & 208 & 41 & $36,7-45,3$ \\
\hline$\geq 9$ & 298 & 59 & $54,7-63,3$ \\
\hline \multicolumn{4}{|c|}{ Classe Chefe de Família } \\
\hline $\mathrm{A} 2$ & 4 & 0,8 & $0,0-1,5$ \\
\hline B1 & 35 & 6,9 & $4,6-9,0$ \\
\hline B2 & 119 & 23,2 & $19,6-26,9$ \\
\hline $\mathrm{C} 1$ & 208 & 40,6 & $36,4-44,9$ \\
\hline $\mathrm{C} 2$ & 122 & 23,8 & $20,1-27,5$ \\
\hline $\mathrm{D}$ & 24 & 4,7 & $2,9-6,5$ \\
\hline \multicolumn{4}{|l|}{ Feijão } \\
\hline$<5$ vezes por semana & 106 & 20,7 & $17,2-24,2$ \\
\hline$\geq 5$ vezes por semana & 406 & 79,3 & $75,8-82,8$ \\
\hline \multicolumn{4}{|l|}{ Frutas } \\
\hline$<5$ vezes por semana & 381 & 74,4 & $70,6-78,2$ \\
\hline$\geq 5$ vezes por semana & 131 & 25,6 & $21,8-29,4$ \\
\hline \multicolumn{4}{|l|}{ Guloseimas } \\
\hline$<5$ vezes por semana & 306 & 59,8 & $55,5-64,0$ \\
\hline$\geq 5$ vezes por semana & 206 & 40,2 & $36-44,5$ \\
\hline \multicolumn{4}{|l|}{ Legumes Cozidos } \\
\hline$<5$ vezes por semana & 447 & 87,3 & $84,4-90,2$ \\
\hline$\geq 5$ vezes por semana & 65 & 12,7 & $9,8-15,6$ \\
\hline \multicolumn{4}{|l|}{ Legumes e Verduras } \\
\hline$<5$ vezes por semana & 442 & 86,3 & $83,4-89,3$ \\
\hline$\geq 5$ vezes por semana & 70 & 13,7 & $10,7-16,6$ \\
\hline
\end{tabular}

Nota: * 6 observações perdidas; IC = Intervalo de Confiança. Fonte: Autores. 
A prevalência da anemia nos adolescentes foi de 3,9\% na amostra. Das 343 (67\%) adolescentes do sexo feminino, 20 ( $\mathrm{p}=0,0013)$ estavam anêmicas (Tabela 2).

Alguns adolescentes não anêmicos apresentaram alterações nos resultados do HCM e do RDW, indicando uma possível deficiência de ferro, embora a anemia ainda não esteja estabelecida, tendo em vista que ela é o último estágio desta deficiência.

Evidenciou-se associação entre sexo e alteração nos níveis de Hb (p-valor = 0,0013), Ht (P-valor = 0,0002), VCM $(\mathrm{P}$ valor $=0,003)$ e CHCM (p-valor =0,0007) pelo teste exato de Fisher. A razão de chances indicada para estes exames foi RC $=$ 0, demonstrando que a chance de alteração destes é $100 \%$ maior no sexo feminino.

As alterações nos índices hematimétricos das adolescentes anêmicas apresentaram microcitose, hipocromia e anisocitose, características comuns da anemia ferropriva.

Tabela 2 - Classificação do Hemograma discriminado por sexo em adolescentes escolares de 2012-2013.

\begin{tabular}{|c|c|c|c|c|}
\hline \multicolumn{5}{|c|}{ Hemoglobina $-\mathbf{H b}$} \\
\hline Sexo & Hb baixa & Hb normal & Total & Fisher (p-valor) \\
\hline Masculino & $0(0 \%)$ & $169(34,2 \%)$ & 169 & \multirow{2}{*}{0,0013} \\
\hline Feminino & $20(100 \%)$ & $323(65,8 \%)$ & 343 & \\
\hline Total & 20 & 492 & 512 & \\
\hline \multicolumn{5}{|c|}{ Hematócritos - Ht } \\
\hline Sexo & Ht baixo & Ht normal & Total & Fisher (p-valor) \\
\hline Masculino & $0(0 \%)$ & $169(34,4 \%)$ & 169 & \multirow{2}{*}{0,0002} \\
\hline Feminino & $21(100 \%)$ & $322(65,6 \%)$ & 343 & \\
\hline Total & 21 & 491 & 512 & \\
\hline \multicolumn{5}{|c|}{ Volume corpuscular Médio - VCM } \\
\hline Sexo & VCM baixo & VCM normal & Total & Fisher (p-valor) \\
\hline Masculino & $0(0 \%)$ & $169(34 \%)$ & 169 & \multirow{2}{*}{0,003} \\
\hline Feminino & $15(100 \%)$ & $328(66 \%)$ & 343 & \\
\hline Total & 15 & 497 & 512 & \\
\hline \multicolumn{5}{|c|}{ Hemoglobina Corpuscular Média - HCM } \\
\hline Sexo & HCM baixa & HCM normal & Total & Fisher (p-valor) \\
\hline Masculino & $4(19 \%)$ & $165(33,6 \%)$ & 169 & \multirow{2}{*}{0,2358} \\
\hline Feminino & $17(81 \%)$ & $326(66,4 \%)$ & 343 & \\
\hline Total & 21 & 491 & 512 & \\
\hline \multicolumn{5}{|c|}{ Concentração de Hemoglobina Corpuscular Média - CHCM } \\
\hline Sexo & CHCM baixa & CHCM normal & Total & Fisher (p-valor) \\
\hline Masculino & $0(0 \%)$ & $169(34,3 \%)$ & 169 & 0,0007 \\
\hline Feminino & $19(100 \%)$ & $324(65,7 \%)$ & 343 & \\
\hline Total & 19 & 493 & 512 & \\
\hline \multicolumn{5}{|c|}{ Red cell distribution width- RDW } \\
\hline Sexo & RDW alto & RDW normal & Total & Fisher (p-valor) \\
\hline Masculino & $17(28,3 \%)$ & $152(33,6 \%)$ & 169 & 0,4669 \\
\hline Feminino & $43(71,7 \%)$ & $300(66,4 \%)$ & 343 & \\
\hline Total & 60 & 452 & 512 & \\
\hline
\end{tabular}

Nota: Fisher $($ p-valor $)=$ Nível de significância do Teste exato de Fisher; Hb= Hemoglobina; Ht = Hematócrito; VCM = Volume corpuscular médio; HCM= Hemoglobina Corpuscular média; CHCM= Concentração de hemoglobina corpuscular média; RDW= Red cell distribuition Width. Fonte: Autores. 
Como apenas o sexo feminino apresentou anemia conforme os critérios adotados pela OMS (WHO, 2009, 2011), todas as análises que seguem foram realizadas apenas com as adolescentes do sexo feminino. Assim, realizou-se análise de associação entre a anemia e as variáveis independentes nos dois grupos das adolescentes, com e sem anemia, através do teste exato de Fisher (Tabela 3).

Para avaliar a classe econômica do chefe de família, foi necessário unir as categorias adjacentes da seguinte forma: classe baixa = D, C2, C1; e classe alta = B2, B1, A. Entre as classes econômicas alta e baixa, o percentual de adolescentes anêmicas foi de $6,4 \%$ e 5,6\%, respectivamente. Como não houve significância estatística $(p=0,7983)$, a anemia não se associou à condição socioeconômica.

Quanto à escolaridade materna, verificou-se que as escolaridades das mães são estatisticamente iguais nos dois grupos ( $p=1,0000)$, não havendo associação desta variável à anemia.

Avaliando a prevalência de anemia de acordo com as faixas etárias, não foi encontrada diferenças estatísticas $(p=1,0000)$.

O estado nutricional foi categorizado em dois grupos: Baixo peso/eutrofia e Sobrepeso/obesidade. Utilizando o teste exato de Fisher ao nível de significância de 5\%, não houve diferença estatística entre anemia e estado nutricional $(p=0,7766)$. 
Tabela 3 - Associação das variáveis Classe econômica, Idade, Escolaridade materna, PCR - Proteína C reativa e Estado nutricional à Anemia em adolescentes escolares do sexo feminino 2012-2013.

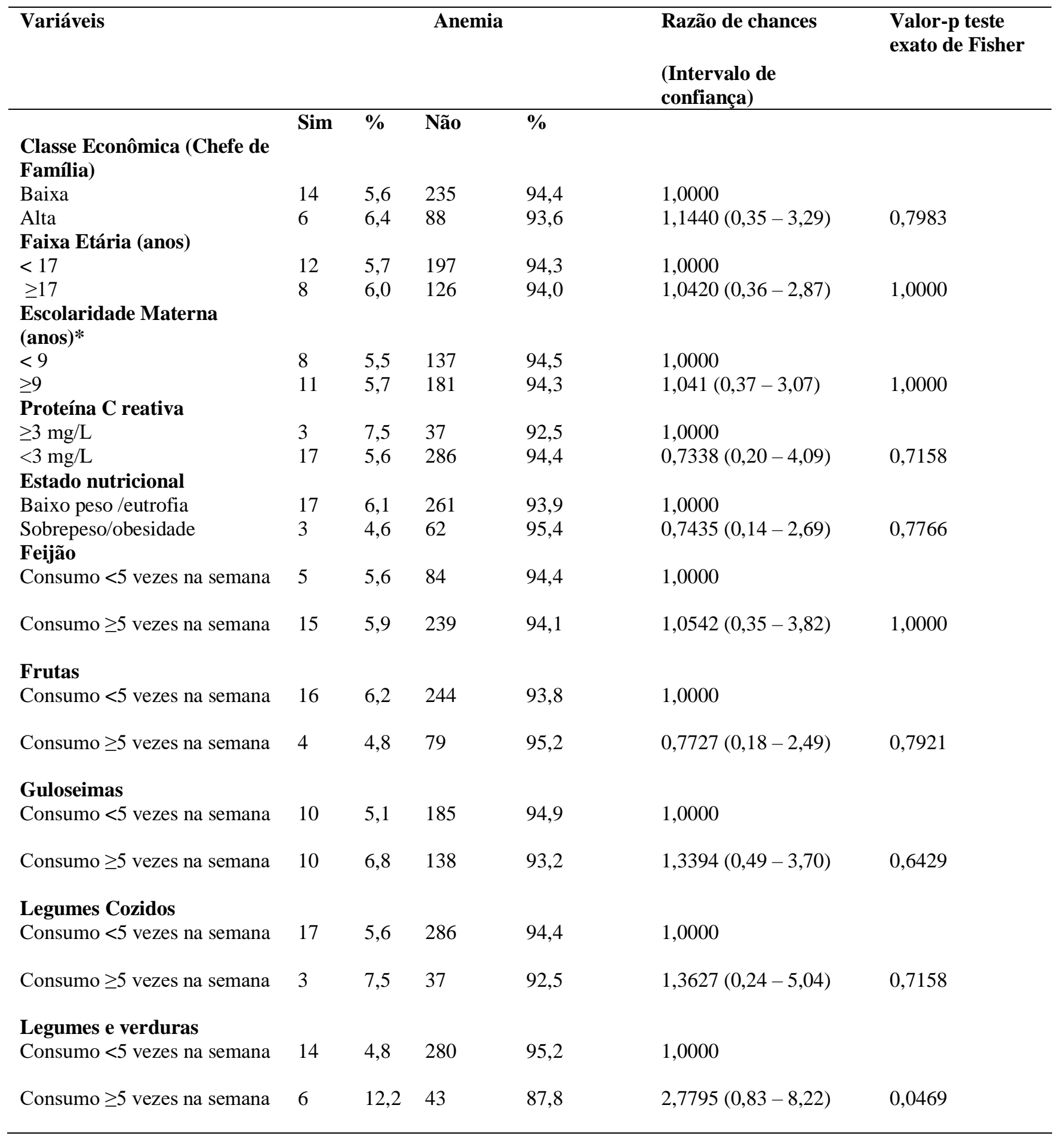

Nota: *6 observações perdidas; P-valor: Nível de significância do Teste exato de Fisher; Fonte: Autores.

\section{Discussão}

Neste estudo, a anemia foi prevalente no sexo feminino em 3,9\% [IC 95\% 2,2 - 5,6], percentual considerado pela OMS como uma prevalência normal (WHO, 2018). Porém, através dos índices hematimétricos, pôde-se inferir a deficiência de ferro em 60 adolescentes de ambos os sexos (11,7\%), podendo incorrer em anemia, caso não sejam corrigidas as inadequações nutricionais. 
Um estudo realizado em Recife-PE, por Mendonça et al, publicado em 2014, apresentou dados semelhantes, com amostra aleatória de 256 adolescentes de ambos os sexos, com idades entre 13 e 18 anos de idade, apresentou maior prevalência de anemia entre o sexo feminino, em todas as faixas etárias ( $\mathrm{p}<0,001)$. No entanto, a prevalência foi de $10,2 \%$ [IC95\% = 6,7-14,5], caracterizando-se como uma prevalência leve (Mendonça et al., 2014)

Corroboram com o presente estudo, a prevalência e os níveis de hemoglobina encontrados entre 409 crianças e adolescentes de escolas públicas da região metropolitana de Curitiba-PR, cujo percentual foi de 2,2\% de anemia, porém, não houve diferença entre os sexos (Spezia et al, 2018).

Outros estudos regionais realizados em Vespasiano, município da região metropolitana de Belo Horizonte-MG, e em Vitória de Santo Antão-PE, com amostra apenas de adolescentes do sexo feminino, apresentaram percentuais de 7,3\% e 13\% de anemia, respectivamente (Beinner et al., 2013; E.C. Costa et al, 2018).

A prevalência da anemia entre adolescentes do sexo feminino é também descrita em estudos internacionais de base populacional, a exemplo do ENSANUT MC 2016, cuja prevalência em adolescentes de ambos os sexos foi de 9,6\% [IC95\% $7,8,11,8$ ] e no sexo feminino de $12 \%$ (De la Cruz-Góngora, 2018). Urrechaga et al., [2016] realizaram um estudo observacional no norte da Espanha, no ano de 2015, com adolescentes de idades entre 15 e 16 anos, no qual foram avaliados 852 meninos e 1407 meninas, e, dentre estes, 8,6\% dos meninos e 7,9\% das meninas estavam anêmicas. Além disso, um percentual de $40 \%$ dos meninos e $63 \%$ das meninas apresentavam deficiência de ferro, levando os autores a considerar o sexo feminino como um grupo de risco para o desenvolvimento de anemia e deficiência de ferro.

De igual modo, na França, Mota et al., em 2019, através do estudo intitulado por "Estimation of the Burden of Iron Deficiency Anemia in France from Iron Intake: Methodological Approach", constataram maior prevalência de anemia entre mulheres em idade reprodutiva, destacando-se adolescentes de 15 a 17 anos, com 22\% de anêmicas, como maiores contribuintes para o DALYs relacionado à anemia, no país. Equitativamente, estudos realizados em outros países apresentaram dados com maior prevalência no sexo feminino, caracterizando-o como grupo de risco para o desenvolvimento desta patologia, seja devido ao consumo insuficiente de ferro e restrições alimentares para perda de peso, seja pelo estirão do crescimento, pela maturação sexual ou pela menarca, que provoca eliminação de ferro orgânico (Alquaiz et al., 2015; Bird et al, 2017; Mota et al., 2019; Skolmowska \& Glabska, 2019; Wirth et al, 2017).

As condições socioeconômicas e a escolaridade materna são fatores determinantes para a prevalência da anemia em adolescentes, por se associarem ao baixo consumo de alimentos ricos em ferro biodisponível, às condições precárias de saneamento e moradia, e ao maior risco de infecções parasitárias (Bezerra et al., 2018; Mota et al, 2019; Spezia et al., 2018) Esta relação foi encontrada em vários estudos (Prasanth, 2017; Shaka \& Wondimagegne, 2018; Thomas et al., 2015). No entanto, a associação da anemia com esses fatores não foi constatada nesta pesquisa, à semelhança de outras publicações (Bezerra et al., 2018; De la Cruz-Góngora et al., 2016).

Neste estudo, a desnutrição e a obesidade não estiveram associadas à prevalência da anemia, tendo em vista que esta foi prevalente entre as adolescentes eutróficas, assim como em outras pesquisas (Costa et al., 2018; De la Cruz-Góngora et al., 2016; Shaka \& Wondimagegne, 2018).

Quanto ao consumo alimentar, no Brasil, a dieta inadequada é o primeiro dos fatores de risco para a carga global de doenças (Malta et al., 2015). Em dois importantes estudos nacionais, esta inadequação foi constatada entre os adolescentes, visto que o hábito alimentar deste grupo foi marcado por um consumo excessivo de alimentos ultraprocessados e um consumo insuficiente de frutas, legumes e verduras (Costa et al., 2018; IBGE, 2016; Souza et al., 2016). Corroborando com estes dados, neste estudo, o consumo alimentar das adolescentes foi marcado por uma ingestão insuficiente de frutas, legumes e verduras.

Guerra et al destacam a importância de investigar não apenas o que é consumido pelo adolescente, mas em que se baseiam suas escolhas e quais os determinantes deste comportamento alimentar, tendo em vista o cenário de insegurança 
alimentar em que vive grande parte da população brasileira. Por causa desse quadro de miséria e fome, que ainda atinge muitas pessoas ao redor do mundo, a Organização das Nações Unidas - ONU, visando a garantia do direito humano à alimentação adequada, estabeleceu metas, firmadas entre os países membros, nos Objetivos de Desenvolvimento do Milênio, sendo o primeiro deles a erradicação da fome e da miséria (Guerra et al., 2018).

O Estado Brasileiro, pactuando com estas ações, implementou políticas de Segurança Alimentar e Nutricional (SAN), visando garantir o direito humano à alimentação adequada e estabeleceu o Pacto Nacional para Alimentação Saudável, por meio do Decreto $\mathrm{n}^{\circ}$ 8.553, de 03 de novembro de 2015, pretendendo viabilizar condições de disponibilidade e consumo de alimentos saudáveis (Brasil, 2015).

\section{Conclusão}

Adolescentes do sexo feminino se constituem como grupo de risco para a prevalência da anemia, seguindo a tendência mundial de países desenvolvidos e em desenvolvimento. Deste modo, faz-se necessário estabelecer ações, no âmbito da saúde pública, que visem rastrear, precocemente, a deficiência de ferro neste público. De igual modo, é de suma importância a promoção de ações intersetoriais que garantam educação e segurança alimentar e nutricional.

Por fim, a partir das contribuições desta pesquisa, sugere-se que trabalhos futuros utilizem estudos com desenhos longitudinais para determinar as relações de causa e efeito, bem como façam uso de outros parâmetros do status do ferro no organismo, como ferritina e ferro sérico. Ademais, para aferir a distribuição da gordura corporal, estudos futuros podem realizar a bioimpedância elétrica, ou desintometria óssea.

\section{Referências}

ABEP - Associação Brasileira de Empresas de Pesquisa (2010). CCEB: Critério de Classificação Econômica Brasil.

Akseer, N., Al-Gashm, S., Mehta, S., Mokdad, A., \& Bhutta, Z.A. (2017). Global and regional trends in the nutritional status of young people: a critical and neglected age group. Ann N Y Acad Sci, 1393(1), 3-20. http://dx. doi.org/10.1111/nyas.13336

Alquaiz, A. M., Khoja, T. A., Alsharif, A., \& Kazi, A. (2015). Prevalence and correlates of anaemia in adolescents in Riyadh city, Kingdom of Saudi Arabia. Public Health Nutr, 18 (17), 3192-200. 10.1017/S1368980015001214

Beinner, M. A., Morais, E. A. H., Filho, J. D. L., Jansen, A. K., Oliveira, S. R., Reis, I. A., \& Reis, E. (2013) Fatores associados à anemia em adolescentes escolares do sexo feminino. Revista Baiana de Saúde Pública, 37(2), 439-51. http://files.bvs.br/upload /S/0100-0233/2013/v37n2/a4452.pdf

Bezerra, A. G. N., Leal, V. S., Lira, P. I. C., Oliveira, J. S., Costa, E. C., Menezes, R. C. E., Siqueira e Campos, F. A. C., \& Andrade, M. I. S. (2018). Anemia e fatores associados em mulheres de idade reprodutiva de um município do Nordeste brasileiro. Rev. bras. epidemiol, 21 , e180001. http://dx.doi.org/10.1590/1980-549720180001

Bird, J. K., Murphy, R. A., Ciappio, E. D., \& McBurney, M. I. (2017). Risk of Deficiency in Multiple Concurrent Micronutrients in Children and Adults in the United States. Nutrients, 9 (7), 655. 10.3390/nu9070655

Costa, C. S., Santos, C. C., Flores, T. R., Wendt, A., Neves, R. G., Assunção, M. C. F., \& Santos, I. S. (2018). Comportamento sedentário e consumo de alimentos ultraprocessados entre adolescentes brasileiros: Pesquisa Nacional de Saúde do Escolar (PeNSE). Cad. Saúde Pública, 34(3), e00021017. //dx.doi.org/10.1590/0102-311x00021017

Costa, E. C., Leal, V. S., Oliveira, J. S., Filho, M. B., Lira, P. I. C., \& Tavares, F. C. P. (2018). Temporal evolution of and factors associated with anemia among women of reproductive age in the state of Pernambuco, Brazil. Cuba Salud. http://convencionsalud2018.sld. cu/index.php/connvencionsalud/2018/paper/view/1749

De la Cruz-Góngora, V., Villalpando, S., \& Shamah-Levy T. (2018). Prevalence of anemia and consumption of iron-rich food groups in Mexican children and adolescents: Ensanut MC 2016. Salud pública de méxico, 60(3), 10.21149/8824

Decreto n 8.553, de 3 de novembro de 2015. (2015). Institui o Pacto Nacional para Alimentação Saudável. Diário Oficial da União.

Guerra, L. D. S., Espinosa, M. M., Bezerra, A. C. D., Guimarães, L. V., \& Martins, M. S. A. S. (2018). Desafios para a Segura nça Alimentar e Nutricional na Amazônia: disponibilidade e consumo em domicílios com adolescentes. Ciênc. saúde coletiva, 23 (12), 4043-54. 10.1590/1413812320182312. 26352016

Hutchinson, C. (2016). A review of iron studies in overweight and obese children and adolescents: a double burden in the young? Eur $J$ Nutr, 55, $2179-97$. $10.1007 / \mathrm{s} 00394-016-1155-7$

Instituto Brasileiro de Geografia e Estatística. Pesquisa Nacional de Saúde do Escolar. 
Lei n ${ }^{\circ}$ 11.274, 6 de fevereiro de 2006. (2006). Estabelece as diretrizes e bases da educação nacional. Diário Oficial da União, Brasília.

Lopez, A., Cacoub, P., Macdougall, I. C., \& Peyrin-Biroulet, L., (2016). Iron deficiency anaemia. The Lancet, 387, 907-16. 10.1016/s0140-6736(15)60865-0 Machado, I. E., Malta, B. C., Bacal, N. S., \& Rosenfeld, L. G. M. Prevalência de anemia em adultos e idosos brasileiros. Rev. bras. epidemiol, 22 (2), E190008. 10.1590/1980-549 720190008.supl.2

Malta, D. C., Felisbino-Mendes, M. S., Machado, I. E., Passos, V. M. A., Abreu, D. M. X., Ishitani, L. H., Velásquez-Meléndez, G., \& Carneiro, M. (2017). Fatores de risco relacionados à carga global de doença do Brasil e Unidades Federadas, 2015. Rev Bras epidemiol, 20 (1), 217-32. 10.1590/19805497201700050018

Mendonça, E. B. S., Muniz, L. F., Arruda, I. K. G., \& Diniz, A. D. (2014). Hemoglobin concentrations and associated factors in adolescentes from Recife, Brazil. Rev. Nutr, 27(5), 537-546. 10.1590/1415-5273 2014000500003

Ministério da Saúde. (2012). Vigitel Brasil 2009: vigilância de fatores de risco e proteção para doenças crônicas por inquérito telefônico. Brasília (DF).

Mota, J. O., Tounian, P., Guillou, S., Pierre, F., \& Membré, J. M. (2019). Estimation of the Burden of Iron Deficiency Anemia in France from Iron Intake: Methodological Approach. Nutrients, 11 (9), 2045. https://doi.org/10.3390/nu11092045

Murillo-Ramos, E., Hurtado-Florez, L., Arciniegas-Yampuezán, N., \& Acevedo-Toro, P. (2016). Hepcidina y parámetros del hierro en donantes de sangre. CES Medicina,158-68. 10.21615/cesmedicina.30.2.3

Nazif, H. K., El-Shaheed, A. A., \& El-Shamy, K. A. I. (2015). Study of Serum Hepcidin as a Potential Mediator of the Disrupted Iron Metabolism in Obese Adolescents. Int J Health Sci Res, 9, 167-74. 10.12816/0024114

Oliveira, B. M. S., Vieira, E. M. M., Quevedo, R. A. V., Figueiredo, A. L. R., \& Coutinho, G. V. P. (2015). Hábitos Alimentares Relacionados ao Desenvolvimento de Doenças Cardiovasculares em Adolescentes. UNICIENCIAS, 19(1). https://revista.pgsskroton.com/index. php/uniciencias/article/view/3156

Pereira, A. S., Shitsuka, D. M., Parreira, F. J., \& Shitsukaet, R. (2018). Metodologia da pesquisa científica. UFSM

Prasanth, R. Prevalence of Anemia in both Developing and Developed Countries around the World. (2017). World J Anemia 1(2), 40-3. 10.5005/jp-journals10065-0009

Shaka, M. F., \& Wondimagegne, Y. A. (2018). Anemia, a moderate public health concern among adolescents in South Ethiopia. PLoS One, $13(7)$, e0191467. 10.1371/journal.pone.0191467

Silva, D. C. A., Assis, D. C. S., Frazão, I. S., Osório, M. M., \& Vasconcelos, M. G. L. (2015). Percepção de adolescentes sobre a prática de alimentação saudável. Cien Saude Colet, 20, 3299-308. http://dx.doi.org/10.1590/1413-81232015201 1.00972015

Skolmowska, D., \& Glabska, D. (2019). Analysis of Heme and Non-Heme Iron Intake and Iron Dietary Sources in Adolescent Menstruating Females in a National Polish Sample. Nutrient, 11(5), 1049. 10.3390/nu11051049

Souza, A. M., Barufaldi, L. A., Abreu, G. A., Giannini, D. T., Oliveira, C. L., Santos, M. M., Leal, V. S., \& Vasconcelos, F. A. G. (2016). ERICA: ingestão de macro e micronutrientes em adolescentes brasileiros. Rev. Saúde Pública, 50 (1), 5s. 10.1590/S01518-8787.2016050006698

Souza, N. P., Lira, P. I. C., Fontbonne, A., Pinto, F. C. L., \& Cesse, E. A. P. (2017). (Mal)nutrition and the new epidemiological trend in a context of development and inequalities. Cien Saude Colet, 22(7), 2257-66. 10.1590/1413-81232017227 .03042017

Spezia, J., Carvalho, L. F. S., Camargo-Filho, M. F. A., Furman, A. E., Utiyama, S. R. R., \& Henneberg, R. (2018). Prevalência de anemia em escolas da região metropolitana de Curitiba, Brasil. Hematol., Transfus. Cell Ther, 40 (2), 151-155. 10.1016/j.htct.2017.11.007

Suhett, L. G., Hermsdorff, H. H. M., Rocha, N. P., Silva, M. A., Filgueiras, M. D. S., Milagres, L. C., Peluzio, M. C. G., \& Novais, J. F. (2019). Increased CReactive Protein in Brazilian Children: Association with Cardiometabolic Risk and Metabolic Syndrome Components (PASE Study). Cardiol Res Pract, 3904568. 10.1155/2019/3904568

Tesfaye, M., Yemane, T., Adisu, W., Asres, Y., \& Gedefaw, L. (2015). Anemia and iron deficiency among school adolescents: burden, severity, and determinant factors in southwest Ethiopia. Adolescent Health, Medicine and Therapeutics, 6, 189-96. 10.2147/ahmt.s94865

Thomas, D., Chandra, J., Sharma, S., Jain, A., \& Pemde, H.K. (2015). Determinants of Nutritional Anemia in Adolescents. Indian Pediatr, 52(10), 867-9. http://dx.doi.org/10.1007/s13312-015-0734-7

Urrechaga, E., Izquierdo-Álvarez, S., Llorente, M.T., \& Escanero, J.F. (2016). Prevalence of Iron Deficiency in Healthy Adolescents. Ann Nutr Disord \& Ther, 3 (2), 1036. https://www.researchgate .net/publication/313218414

Wirth, J. P., Woodruff. B. A., Engle-Stone, R., Namaste, S. M. L., Temple, V. J., Petry, N., Macdonald, B., Suchdev, P. S., Rohner, F., \& Aaron, G. J. (2017). Predictors of anemia in women of reproductive age: Biomarkers Reflecting Inflammation and Nutritional Determinants of Anemia (BRINDA) project. Am $J$ Clin Nutr, 106 (1), 416S-27S. 10.3945/ajcn.116.143073

World Health Organization. (1995). Physical Status: the study and interpretation of anthropometry: report of a WHO expert committee.

World Health Organization. (2011). Haemoglobin concentrations for the diagnosis of anaemia and assessment of severity. Vitamin and Mineral Nutrition Information System.

World Health Organization. (2018). Guideline: implementing effective actions for improving adolescent nutrition, 